\title{
Median Nerve Function of Individuals With and Without a Parental History of Hypertension
}

\author{
A thesis presented to \\ the faculty of \\ the College of Arts and Sciences of Ohio University
}

In partial fulfillment of the requirements for the degree Master of Science

Diane M. Copley

November 2010

(C) 2010 Diane M. Copley. All Rights Reserved. 
This thesis titled

Median Nerve Function of Individuals With and Without a Parental History of Hypertension

by

DIANE M. COPLEY

has been approved for

the Department of Psychology

and the College of Arts and Sciences by

Christopher R. France

Professor of Psychology

Benjamin M. Ogles

Dean, College of Arts and Sciences 


\begin{abstract}
COPLEY, DIANE M., M.S., November 2010, Psychology

Median Nerve Function of Individuals With and Without a Parental History of

Hypertension
\end{abstract}

Director of Thesis: Christopher R. France

Hypertension is a highly prevalent health condition that puts individuals at risk for developing cardiovascular disease, stroke, and kidney disease. Early detection and prevention are important elements in avoiding future health complications. Although hypertension is typically viewed as a "silent killer" due to the absence of subjective symptoms, there is significant evidence that hypertensives as well as normotensives at increased risk for hypertension exhibit hypoalgesia (i.e., increased pain threshold and tolerance levels). Although the underlying mechanism for this hypoalgesia remains unclear, most of the existing research has focused on central rather than peripheral nervous system explanations. In contrast, a recent study (Edwards, Ring, McIntyre, Winer, \& Martin, 2008) demonstrated that patients with essential hypertension show impairment in median nerve function as indexed by reduced sensory action potentials. These findings present the possibility that impairments in peripheral nerve function may help explain hypoalgesic responses in those with hypertension, and possibly among those at increased risk for high blood pressure. Accordingly, the aim of the current study was to examine median nerve function and pain threshold/tolerance levels in individuals with and without a parental history of hypertension to determine if expected differences in 
pain responsivity are mediated by individual differences in sensory nerve function. Seventy-nine participants underwent study procedures and were divided into two groups: positive parental history of hypertension and negative parental history of hypertension. The primary hypothesis was not supported, as there was no significant difference in sensory nerve function among the two groups. Combined with prior evidence from hypertensive participants, the present findings suggest that deficits in median nerve function may occur as a response to hypertension.

Approved:

\author{
Christopher R. France \\ Professor of Psychology
}




\section{Acknowledgements}

I would like to thank my thesis advisor, Dr. Christopher France, for his extensive encouragement and support throughout the process of data collection and writing. I am grateful to my committee members, Drs. Julie Suhr and Jeffrey Vancouver for their willingness to serve as my committee members and for their helpful feedback and suggestions. Thank you to the other members of Dr. France's lab that have also provided me with support and helpful suggestions. Lastly, I would like to thank my family and friends for all of their love and encouragement. A special thank you goes out to my

family whom has always encouraged me to find my own path in life and to never give up. Without them, I would not be where I am today. 
Table of Contents

Page

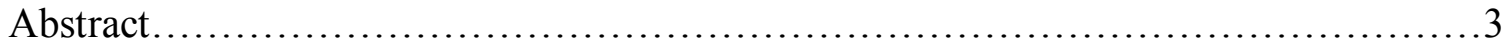

Acknowledgements.......................................................

List of Tables...............................................................

List of Figures......................................................... 9

Introduction........................................................... 10

Materials and Methods..................................................... 13

Participants....................................................... 13

Preparation............................................................. 13

Apparatus......................................................... 14

Procedure......................................................... 14

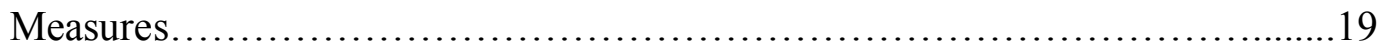

Analysis of Sensory Action Potential Waveform Data......................20

Results........................................................................

Study Participants.................................................21

Parental History of Hypertension and Hypoalgesic Responses..................23

Median Nerve Function...............................................25

Correlation between Systolic Blood Pressure and Pain.........................26

Discussion............................................................... 28

References.............................................................. 34

Appendix A: Study Forms and Measures................................................ 


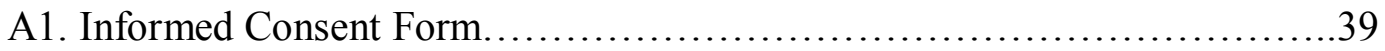

A2. Health History and Parent Contact Form.................................43

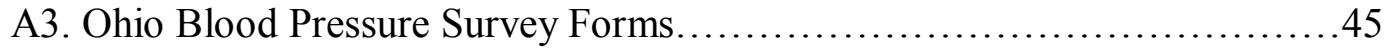

A4. Numerical Pain Rating Intensity Scale..................................47

A5. Parent Letter........................................................ 48

A6. McGill Pain Questionnaire- Short Form......................................49

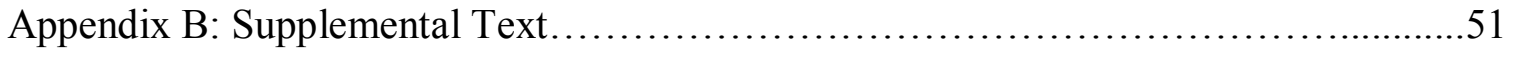


List of Tables

Page

Table 1: Mean (SD) Age, Body Mass Index (BMI), Systolic Blood Pressure (SBP), and Diastolic Blood Pressure (DBP) as a Function of Parental History of Hypertension. ...................................................24

Table 2: Mean (SD) for pain threshold and total pain rating index scores on the McGill Pain Questionnaire as a Function of Gender and Parental History of

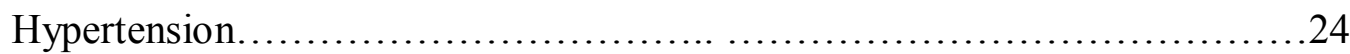

Table 3: Results of 2 group (PH+/PH-) X 2 sex analysis of variance for pain threshold and total pain rating index scores on the McGill Pain Questionnaire............25

Table 4: Results of 2 group (PH+/PH-) X 2 sex analysis of covariance and analysis of variance on sensory action potential amplitudes.......................27

Table 5: Correlation between systolic blood pressure and pain threshold and MPQ total

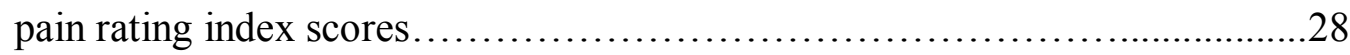




\section{List of Figures}

Page

Figure 1: Electrode placement on palmar side of index finger for sensory nerve EMG ................................................................... 16

Figure 2: Median Nerve Anatomical Diagram.......................................16

Figure 3: Electrode over median nerve at proximal wrist crease........................17

Figure 4: Electrical stimulation electrode placement on forearm......................18

Figure 5: Participant attrition flowchart........................................22

Figure 6: Grand averages of sensory action potential amplitude waveforms of positive and negative parental history groups.....................................27 
Introduction

Hypertension afflicts over 65 million adults in the United States (Ong, Cheung, Man, Lau, \& Lam, 2007) and it is estimated that the worldwide prevalence of hypertension is approximately one billion individuals (World Health Report, 2002). These staggering statistics may continue to rise if control, treatment, and prevention of this disease are not promoted and monitored. Currently, many cases of hypertension are left untreated because individuals with the condition are usually asymptomatic and therefore unaware that they are in need of treatment (Ong et al., 2007). Recent estimates are that approximately $30 \%$ are unaware that they have hypertension and that more than $40 \%$ of individuals are not receiving hypertension treatment (JNC 7, 2004).

\section{Risks Related to Hypertension}

Hypertension has been linked to the development of cardiovascular disease, stroke, and kidney disease. The risk of developing these health complications increases progressively and linearly with respect to blood pressure values (JNC 7, 2004).Therefore, hypertension can lead to premature morbidity and mortality (JNC 7, 2004). Early prevention is the key to stopping the deleterious effects of hypertension, and therefore efforts must be made to obtain early detection of elevated blood pressure levels. Research on both human and laboratory animals indicate that hypoalgesia (decreased sensitivity to pain) may serve as an early risk indicator for hypertension among healthy young adults who do not have any other symptoms of hypertension. 
Parental History of Hypertension and Hypoalgesia

A number of studies have looked at hypoalgesia as a risk indicator for individuals with a parental history of hypertension (France, Ditto, \& Adler, 1991; France, Adler, France, \& Ditto, 1994; France \& Stewart, 1995; Stewart \& France, 1996; al'Absi, Buchanan, \& Lovallo, 1996; France, French, Page, Bonk, Meade, Stewart et al., 1996; Bragdon, Light, Girdler, \& Maixner, 1997; Page \& France, 1997; Ditto, France, \& France, 1997; Ditto, Pihl, Seguin, Boulerice, \& Tremblay, 1998; D’Antono, Ditto, Rios, \& Moskowitz, 1999; Guasti et al., 1999; al'Absi, Buchanan, Marrero, \& Lovallo, 1999; al' Absi, Petersen, \& Wittmers, 2000; Campbell \& Ditto, 2002; Campbell et al., 2002; Campbell, Ditto, Seguin, Sinray, \& Tremblay, 2003; France, al'Absi, Ring, France, Brose, Spaeth, et al., 2005). Many of these studies have found that the presence of hypoalgesia precedes the development of hypertension. The majority of these studies took place in a laboratory setting while some occurred in a naturalistic setting (ex. during blood donation), and the types of pain stimuli and procedures have ranged from thermal stimulation, electrical stimulation, dental pulp electrical stimulation, arm ischemia, venipuncture, nociceptive withdrawal reflex, and thigh cuff and finger pressure. Results have not been consistent across studies, but many researchers have found a significant relationship between having a parental history of hypertension and reporting increased pain threshold levels.

The mechanism behind the hypoalgesic response in hypertensives and those at risk for hypertension is not well understood. Whereas many studies have hypothesized that hypoalgesia may result from differences in central pain processing, one study 
(Edwards et al., 2008) provided evidence that hypoalgesic responses may be mediated, at least in part, by peripheral mechanisms. Specifically, Edwards and colleagues (2008) examined nerve function and pain perception in unmedicated individuals with hypertension and normotensive individuals. Assessment of nerve function was performed by stimulating the median nerve to measure sensory action potential amplitudes and conduction velocities (Ferry, Silman, Pritchard, Keenan, \& Croft, 1998). They found that individuals with hypertension had lower sensitivity to cutaneous stimulation and reduced pain perception. They also found that individuals with hypertension had lower sensory action potential amplitudes than normotensive individuals. Combined with a lack of differences between the two groups in sensory and compound motor median nerve velocities, these findings indicated that hypertension does not affect neuronal myelination but may be associated with axonal loss. In contrast to the central hypoalgesia hypothesis that is often provided in the literature, these findings may provide a simpler explanation for the hypoalgesic responses displayed in individuals with hypertension and possibly in those at risk for hypertension. Specifically, because axonal loss results in deficits in spinal cord activation (Johnson, Ryals, \& Wright, 2007), observed differences in pain perception among individuals with and without hypertension may be due, at least in part, to differences in peripheral processing of pain signals.

\section{The Present Study}

Because it is currently not known if hypertension leads to changes in median nerve function or if such changes precedes high blood pressure onset in those at risk for hypertension, the current study examined peripheral nerve function of normotensive 
individuals with and without a parental history of hypertension. It was hypothesized that, compared to individuals without a parental history of hypertension, those with a parental history of hypertension (defined as having one or two parents with a diagnosis of hypertension) would exhibit (1) higher electrical stimulation pain thresholds and (2) deficits in median nerve function, as indicated by smaller sensory action potential amplitudes.

Materials and Methods

\section{Participants}

Ohio University college students $(n=114)$ were recruited for this study through the Psychology Department's online research participant recruitment system. Participants were assessed to ensure that they met the eligibility requirements for this study. The inclusion criteria required that participants were between the ages of 18-30, had no history of carpal tunnel syndrome or peripheral neuropathy, no use of prescription pain medication on a daily basis, no use of non-prescription pain medicine 24 hours prior to testing, and had no major health issues including cardiovascular, pulmonary, and renal diseases. Participation was voluntary and this study was approved by the Institutional Review Board of Ohio University. Written informed consent was provided by all participants and they were compensated with two research participation credits.

\section{Preparation}

Participants were asked to refrain from alcohol, caffeine, nicotine, and vigorous exercise for four hours prior to their study participation. Once they arrived at the laboratory, participants completed an oral and written informed consent process (see 
Appendix A1). If they agreed to participate, they signed the consent form and then they were administered an inclusion questionnaire to make certain they met all components of the inclusion criteria. In addition, they provided the experimenter with their biological parents' mailing addresses (see Appendix A2) so that the Ohio Blood Pressure History Survey (see Appendix A3) could be mailed to their parents. The participants' height and weight was measured using a stadiometer to determine their Body Mass Index (BMI) in $\mathrm{kg} / \mathrm{m}^{2}$.

\section{Apparatus}

Data collection occurred with the use of an IBM ThinkPad laptop computer (Model \#1844) and Spike2 software was used to record sensory nerve EMG.

Electocutaneous stimulation was delivered using a Digitimer, DS7A constant current stimulator. Electromyographic (EMG) activity was recorded at $10 \mathrm{KHz}$ using an Astro Med Inc., Grass Technologies EMG amplifier set to x10,000 gain amplification and a 30$300 \mathrm{~Hz}$ bandwidth. Systolic and diastolic blood pressure (in $\mathrm{mmHg}$ ) and heart rate (in bpm) were recorded using an automated Critikon, Dinamap Compact $\mathrm{T}$ blood pressure monitor. Surface hand temperature was recorded during the median nerve testing procedure using a Davicon T33 (Neurodyne Medical) temperature monitor.

\section{Procedure}

\section{Electrode Placement}

After receiving informed consent and parental contact information, the participants had their height and weight assessed to determine their body mass index (BMI). The next step involved preparing the participants for electrode placement. The 
skin was thoroughly cleaned with an alcohol swab and slightly abraded with the use of an abrasive gel at the electrode placement sites to reduce impedance. Sensory nerve EMG was recorded using a surface electrode placed on the palmar side of the index finger of the dominant hand with a $3 \mathrm{~cm}$ interelectrode distance (see Figure 1). A ground electrode was located over the medial wrist bone. The median nerve (see Figure 2) was stimulated by applying an electrocutaneous stimulus to the proximal wrist crease between the central Palmaris longus tendon and the flexor capri radialis tendon (see Figure 3). The surface electrodes for median nerve stimulation had a $3 \mathrm{~cm}$ inter-electrode distance. After the area was prepped and the electrodes were applied, the participants had the pain rating scale explained to them. During the median nerve test and electrical pain threshold assessment, participants provided pain ratings after each stimulation using a 0-100 scale (see Appendix A4) with anchors of 0 "no sensation perceived", 1 "just noticeable sensation", 25 "uncomfortable", 50 "pain”, 75 "very painful”, and 100 "maximum tolerable pain".

\section{Phase 1:Median Nerve Test}

The median nerve test began by locating the optimal stimulation site for the median nerve at the wrist crease. The DS7A was set at $6 \mathrm{~mA}$ and was triggered by a Spike2 program every 6 seconds to determine the best location to secure the stimulating electrode. Once the optimal site was located, the experimenter attached the electrode. 


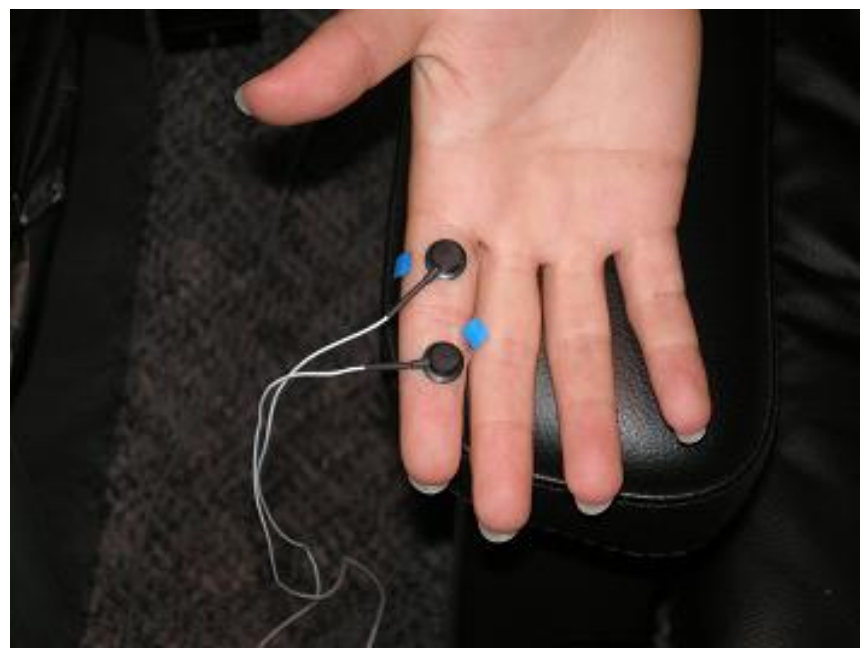

Figure 1. Electrode placement on palmar side of index finger for sensory nerve EMG.

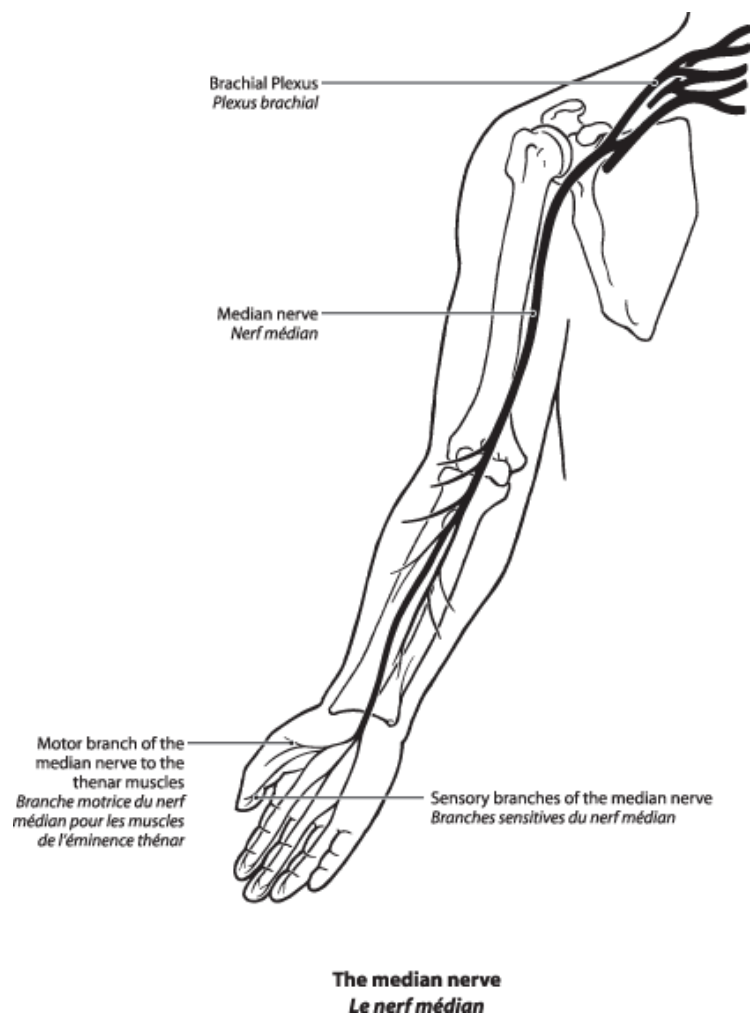

Figure 2. Median Nerve Anatomical Diagram.

Note. Reprinted from "Carpal Tunnel Syndrome".

Retrieved October 5, 2008 from www.wsiat.on.ca/images/mlo/mediannerve.gif.

Copyright March 2003 by The Workplace Safety and Insurance Appeals Tribunal. 


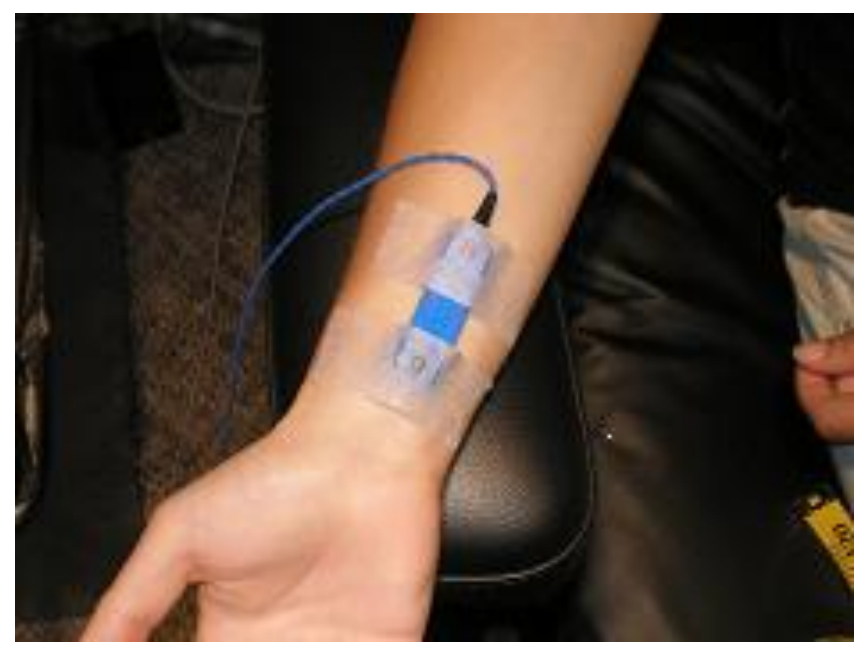

Figure 3. Electrode over median nerve at proximal wrist crease.

\section{Determining Supramaximal Threshold of Median Nerve}

The program began by delivering a $4 \mathrm{~mA}$ stimulation and a pain rating (from 0 100) was obtained after each stimulation. The stimulation increased in $2 \mathrm{~mA}$ steps until a supramaximal sensory action potential was observed from the EMG signal. The intensity was manually increased until the amplitude of the sensory action potential waveform reached its maximum peak (which was confirmed by increasing and decreasing the stimulation intensity in $2 \mathrm{~mA}$ steps to ensure reliability of the response). The peak value (in $\mathrm{mA}$ ) was used in the subsequent assessment of median nerve function.

\section{Assessment of Median Nerve Function}

The last phase of the median nerve test involved having the DS7A set to the $\mathrm{mA}$ level associated with the supramaximal threshold level (determined by the procedure explained above) and having a series of 36 stimulation trials delivered, on average, at 7 second intervals (i.e., randomly between 5-7 seconds). The participant's hand 
temperature was measured throughout the trials to ensure that the hand temperature remained between 31 and 35 degrees Celsius. If the participant's hand temperature fell outside of that range, a heating pad or an ice pack was used to warm/cool the hand down as needed before proceeding.

\section{Phase 2: Electrical Pain Threshold Assessment}

To assess electrocutaneous pain threshold, a stimulation electrode was wrapped around the participant's dominant forearm (see Figure 4). Electrical stimulation began at $0 \mathrm{~mA}$ and increased in $2 \mathrm{~mA}$ increments until the participant provided a rating of 50 or greater using the numerical pain intensity rating scale. The $\mathrm{mA}$ intensity at this rating

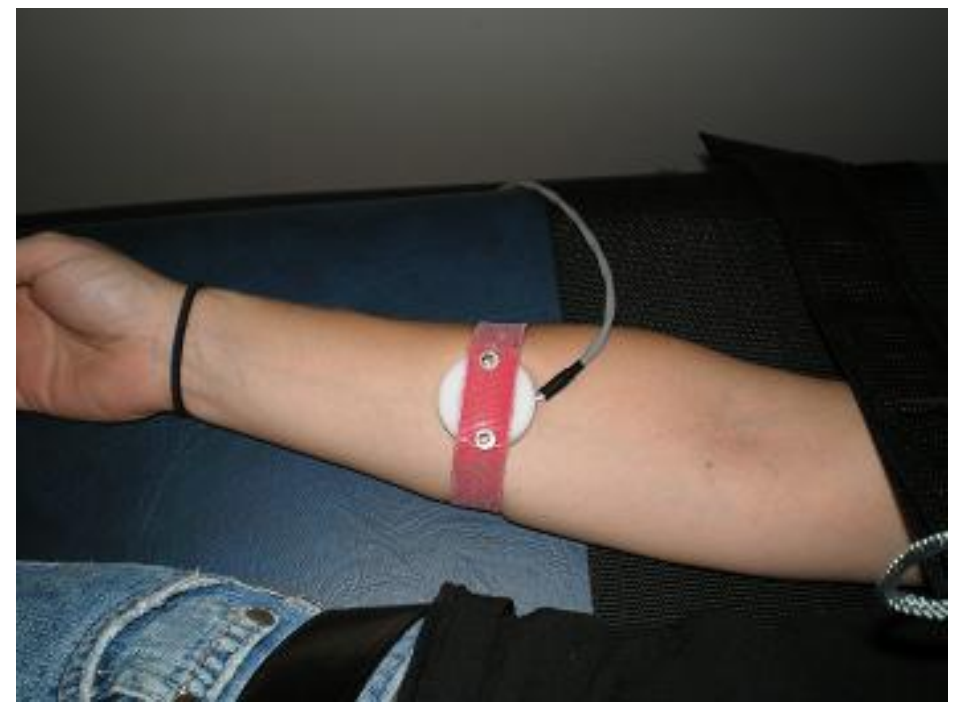

Figure 4. Electrical stimulation electrode placement on forearm.

level was recorded. This procedure was repeated two more times, and the average of the three ascending trials was considered their electrical pain threshold. For safety and ethical reasons, stimulation intensity did not exceed $40 \mathrm{~mA}$ or a subjective report of 100 
“maximum tolerable pain". After completing the electrical stimulation trials, participants completed the McGill Pain Questionnaire - Short Form to measure their overall evaluation of pain during the assessment.

\section{Phase 3: Resting Blood Pressure Measurement}

The concluding phase of the study involved the participant sitting quietly for fifteen minutes while their resting blood pressure and heart rate levels were measured at three minute intervals (i.e., $0,3,6,9,12$, and 15 minutes). Mean levels of blood pressure and heart rate were calculated by averaging the last three readings. Shapiro and colleagues (1996) recommend averaging multiple measurements to ensure precision in estimating blood pressure levels. In addition, they encouraged researchers to consider any psychological stressors, such as anticipatory anxiety, that may affect blood pressure levels. Therefore, we concluded the sessions with blood pressure measurements to account for these influential factors.

\section{Measures}

\section{Parental Blood Pressure History Screening}

The biological parents of each participant received a letter (see Appendix A5) and a copy of the Ohio Blood Pressure History Survey (Page \& France, 2001) via regular mail. The survey (see Appendix A3) asked each parent to provide the following health information: age, length of time since their last blood pressure screening, their typical blood pressure, prior diagnosis of hypertension as well as medication prescribed, history of diabetes or kidney disease, other health problems, and family history of hypertension. The Ohio Blood Pressure History Survey has been shown to be a valid and reliable self- 
report measure of parental hypertension history, with an overall accuracy of $94.2 \%$, a sensitivity of $95.4 \%$, and a specificity of $92.4 \%$ as compared to other medical records (Page \& France, 2001). Based on parental responses to the survey, participants were assigned to the positive parental history of hypertension $(\mathrm{PH}+)$ group if they had at least one parent with a prior diagnosis of high blood pressure that was treated with medication. If neither parent reported a prior diagnosis of hypertension, the participant was assigned to the negative parental history of hypertension (PH-) group. Participants were not included in the current research if their parents failed to return the survey or either biological parent reported a prior diagnosis of hypertension without medication treatment. In such cases a new participant was recruited and tested to achieve the final sample size of $\mathrm{N}=79$.

\section{McGill Pain Questionnaire - Short Form}

The McGill Pain Questionnaire - Short Form (see Appendix A6) was used to obtain multidimensional ratings of pain intensity (Melzack, 1987). Following the electrical stimulation procedure, participants filled out the MPQ-SF to rate 15 pain descriptors on a four point scale with the following anchors of 0 (none), 1 (mild), 2 (moderate), and 3 (severe). The MPQ-SF is a reliable and validated measure that has been used across a variety of clinical and research applications (Melzack, 1987).

\section{Analysis of Sensory Action Potential Waveform Data}

In order to analyze and compare the average sensory action potential waveform data for the positive and negative parental history of hypertension groups, we had to look at the waveform data on an individual level. We looked through all 36 waveforms for 
each participant and eliminated participants that had waveforms that were of poor recording quality. We determined that a participant that had more than $25 \%$ of poor quality waveform data would be elminated from the analyses. Therefore, we eliminated 5 participants with a positive parental history and 6 with a negative parental history from our analyses in order to provide an accurate representation of median nerve function between the two groups. As a result, our analyses of median nerve function consist of 68 of the 79 participants.

\section{Results}

\section{Study Participants}

As can be seen in Figure 5, one hundred and fourteen individuals were recruited for the study. Participants were excluded from analyses if they were unwilling or unable to provide parent contact information $(n=6)$, if their skin impedance was too high after preparation $(n=2)$, if there were equipment problems $(n=1)$, if their parental history of hypertension was not confirmed $(n=21)$, or if their parent(s) reported a diagnosis of hypertension that was not treated with medications $(n=3)$ or was associated with diabetes or kidney disease $(n=2)$. Following these exclusions, the final sample was 79 participants.

Our sample was predominantly Caucasian (91.1\%), 3.8\% were Asian, 2.5\% were African American, and 2.5\% were Hispanic or Latino. There were no significant differences between the groups in racial composition. Mean age, body mass index, systolic blood pressure, and diastolic blood pressure are displayed in Table 1 as a 


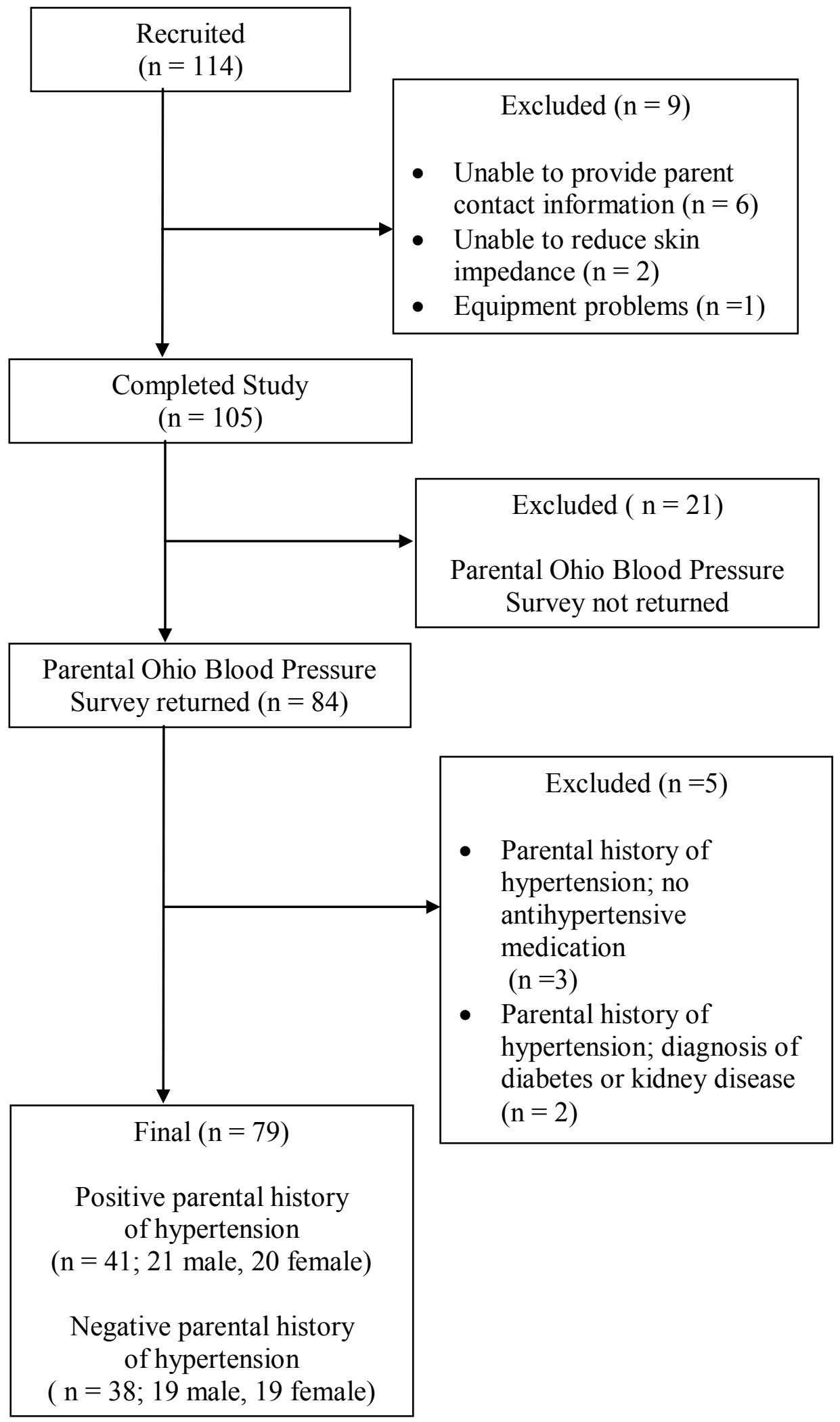

Figure 5. Participant attrition flowchart. 
function of parental history of hypertension.

There were no significant differences between the groups in body mass index, however on average the offspring of hypertensive parents were older, $(t(77)=-2.43, \mathrm{p}<$ $.05)$, and had higher systolic blood pressure, $(t(77)=-2.61, \mathrm{p}<.05)$, and diastolic blood pressure $(t(77)=-2.23, \mathrm{p}<.05)$.

Parental History of Hypertension and Hypoalgesic Responses

To examine the first hypothesis, that individuals with a parental history of hypertension would have reduced perception of pain from electrical stimulation as compared to individuals without a parental history of hypertension, separate 2 group (PH+/PH-) X 2 sex (male/female) analyses of variance (ANOVA) were conducted to compare 1) pain threshold (in $\mathrm{mA}$ ) during electrical stimulation of the forearm and 2) total pain rating index scores on the McGill Pain Questionnaire. Sex was included as a variable based on previous evidence of differential pain responses of men and women with and without a parental history of hypertension. Average pain threshold levels and total pain rating index scores on the McGill Pain Questionnaire as a function of gender and parental history of hypertension are displayed in Table 2. As can be seen in Table 3, there were no significant differences between groups on either pain threshold $(\mathrm{PH}+: M=$ $24.70, S D=10.67$ vs. $\mathrm{PH}-: M=23.96, S D=11.53$ ), or on total pain rating index scores 
Table 1

Mean (SD) Age, Body Mass Index (BMI), Systolic Blood Pressure (SBP), and

Diastolic Blood Pressure (DBP) as a Function of Parental History of Hypertension

\begin{tabular}{lccc}
\hline & Positive Parental History $(\mathrm{n}=41)$ & Negative Parental History $(\mathrm{n}=38)$ \\
\hline Variable & $\mathrm{M}(\mathrm{SD})$ & $\mathrm{M}(\mathrm{SD})$ & $\mathrm{p}$ \\
\hline Age $($ years$)$ & $21.6(4.0)$ & $19.8(2.4)$ & .02 \\
BMI (m/kg $\left.{ }^{2}\right)$ & $23.9(4.0)$ & $23.3(3.8)$ & .45 \\
SBP $(\mathrm{mmHg})$ & $111.7(12.6)$ & $104.6(11.4)$ & .01 \\
DBP $(\mathrm{mmHg})$ & $67.8(8.2)$ & $63.8(7.4)$ & .03 \\
\hline
\end{tabular}

Table 2

Mean (SD) for pain threshold and total pain rating index scores on the McGill Pain

Questionnaire as a Function of Gender and Parental History of Hypertension

\begin{tabular}{lcccc}
\hline \multicolumn{3}{c}{ PH- } & \multicolumn{2}{c}{$\mathrm{PH}+$} \\
\hline \multirow{2}{*}{ Variable } & Male & Female & Male & Female \\
& M (SD) & M (SD) & M (SD) & M (SD) \\
\hline Pain Threshold & $23.2(12.0)$ & $24.8(11.3)$ & $28.0(11.0)$ & $21.3(9.3)$ \\
MPQ & $4.6(3.6)$ & $5.4(2.7)$ & $4.6(3.5)$ & $5.3(3.2)$ \\
\hline
\end{tabular}


Table 3

Results of 2 group (PH+/PH-) X 2 sex analysis of variance for pain threshold and total pain rating index scores on the McGill Pain Questionnaire

\begin{tabular}{lllll}
\hline Variables & Factor & $\boldsymbol{F}$ & $\boldsymbol{p}$ & $\mathbf{\eta}_{\mathbf{p}}{ }^{\mathbf{2}}$ \\
\hline Pain & Group & 0.40 & .53 & .01 \\
Threshold & Sex & 0.35 & .56 & .01 \\
& Group x Sex & 2.69 & .11 & .04 \\
& Age & 3.40 & .07 & .05 \\
& SBP & 0.04 & .84 & .00 \\
MPQ Total & Group & 0.37 & .55 & .01 \\
Pain Rating & Sex & 0.15 & .70 & .00 \\
& Group $x$ Sex & 0.10 & .96 & .00 \\
& Age & 1.32 & .82 & .00 \\
& SBP & 0.63 & .25 & .02 \\
& DBP & 1.35 & .25 & .01 \\
\hline
\end{tabular}

$(\mathrm{PH}+: M=4.90, S D=3.36$ vs. $\mathrm{PH}-: M=4.97, S D=3.18)$. In addition, there were no significant main effects of sex or interactions of group by sex for either pain threshold or total pain rating index scores, as well as no significant differences by group for either pain threshold or total pain rating index scores after controlling for age, systolic blood pressure, and diastolic blood pressure.

\section{Median Nerve Function}

To examine the second hypothesis, that individuals with a parental history of hypertension would show lower median nerve sensory action potential amplitudes compared to individuals without a parental history of hypertension, grand averages were computed so that a single waveform was used to represent the mean response across all 
36 trials (see Figure 6). Using the grand average waveform, action potential amplitudes were calculated (in $\mu \mathrm{V}$ ) from baseline to the peak of the negative deflection. A 2 group (PH+/PH-) X 2 sex (male/female) analysis of covariance (ANCOVA) was performed with sensory action potential amplitudes as the dependent variable and body mass index (BMI) as the covariate. As can be seen in Table 4, the results indicated that there were no significant differences between groups on sensory action potential amplitudes $(\mathrm{PH}+: M=$ $-14 \mu \mathrm{V}, S D=1.0$ vs. PH-: $M=-15 \mu \mathrm{V}, S D=1.0)$. Similar results were obtained when BMI was not included as a covariate. In addition, there were no significant main effects of sex or interactions of group by sex for sensory action potential amplitudes, as well as no significant differences by group after controlling for age, systolic blood pressure, and diastolic blood pressure.

\section{Correlation between Systolic Blood Pressure and Pain}

As can be seen in Table 5, Pearson $r$ correlation analyses were conducted to examine the relationships between systolic blood pressure and average pain threshold, and systolic blood pressure and total pain rating index scores on the MPQ as a function of gender and parental history status. There were no significant relationships observed among these variables. 


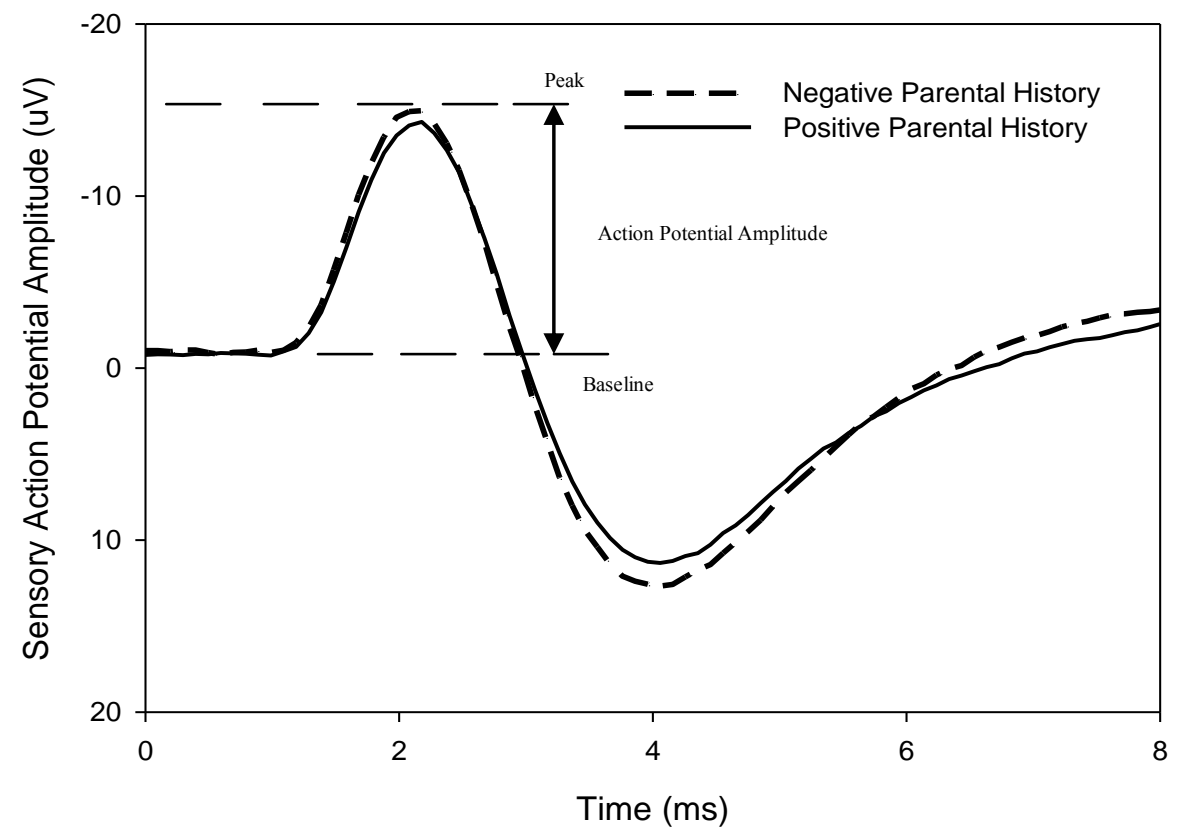

Figure 6. Grand averages of sensory action potential amplitude waveforms of positive and negative parental history groups.

Table 4

Results of 2 group (PH+/PH-) X 2 sex analysis of covariance and analysis of variance on sensory action potential amplitudes

\begin{tabular}{lllll}
\hline Variable & Factor & $\boldsymbol{F}$ & $\boldsymbol{p}$ & $\boldsymbol{\eta}_{\mathbf{p}}{ }^{2}$ \\
\hline Sensory & Group & 0.16 & .69 & .00 \\
Action & Sex & 3.60 & .06 & .06 \\
Potential & Group x Sex & 0.34 & .56 & .01 \\
Amplitude & BMI & 0.12 & .73 & .00 \\
& Age & 0.96 & .33 & .02 \\
& SBP & 3.04 & .09 & .05 \\
& DBP & 2.87 & .10 & .05 \\
\hline
\end{tabular}


Table 5

Correlation between systolic blood pressure and pain threshold and MPQ total pain rating index scores

\begin{tabular}{lll}
\hline & Pain & MPQ Total Pain \\
& Threshold & Rating Index \\
\hline Entire sample $(\mathrm{n}=79)$ & 0.13 & -0.09 \\
Males only $(\mathrm{n}=40)$ & 0.05 & -0.11 \\
Females only $(\mathrm{n}=39)$ & 0.10 & 0.08 \\
Offspring of hypertensives only $(\mathrm{n}=41)$ & 0.26 & 0.04 \\
Offspring of normotensives only $(\mathrm{n}=38)$ & -0.03 & -0.26 \\
\hline
\end{tabular}

\section{Discussion}

The aim of this study was to examine differences in pain threshold and median nerve function in individuals with and without a parental history of hypertension. We hypothesized that, compared to individuals without a parental history of hypertension, those with a parental history of hypertension would exhibit higher electrical stimulation pain thresholds and lower median nerve sensory action potential amplitudes. However, we did not find any differences in pain threshold or median nerve sensory action potential amplitudes among the two groups.

In the absence of any differences in pain perception among the two groups, the potential differences in sensory median nerve function were not as relevant, but median nerve function was still tested. We did not find any differences in median nerve function among individuals with and without a parental history of hypertension implying that median nerve deficits may occur after the development of hypertension. Edwards and colleagues (2008) stated that hypertension may cause axonal loss contributing to 
neuropathy. The development of neuropathy would help explain their decreased perception or sensation of pain.

Also, in comparison to the results found by Edwards and colleagues (2008), we did not find any differences in amplitude among the two groups and our onset latencies of the sensory action potential waveform were much faster than their sample (i.e. $1.5 \mathrm{~ms}$ vs. 3.5ms). Research has found that onset latencies of median nerve action potentials increase with age (Salerno et al., 1998; Radecki, 1995), which may explain why our sample of college students have faster onset latencies than the middle-aged sample tested by Edwards et al. (2008). Specifically, Radecki (1995) observed that onset latencies ranged from 2.0 to $4.8 \mathrm{~ms}$ in a sample of 18 to 65 year old participants, with slower latencies in older participants.

Previous studies have provided results indicating that changes in median nerve function may occur subsequent to the development of hypertension. A previous study conducted by Sabbatini and colleagues (2001) provided the antihypertensive treatment nicardipine (a dihydropyridinetype $\mathrm{Ca}+2$ antagonist) to the spontaneously hypertensive rat to see if there would be any differences in their peripheral nerve vascular function. The spontaneously hypertensive rat has been shown to have hypoalgesia and vascular impairments before the development of hypertension (Sitsen \& de Jong, 1983; Sabbatini et al., 2001).They found some modest effects that partially reversed vascular impairments in the spontaneously hypertensive rat after hypertensive treatment, and were able to conclude that there are hypertension-related changes in peripheral nerve function. Their findings imply that hypertension may be a risk factor of ischemia of the peripheral 
nerves. These study findings imply that physiological changes in the nerves may only follow hypertension, and may help explain why we may not have found effects in healthy positive parental history of hypertension individuals versus healthy negative parental history of hypertension individuals.

There are a number of potential explanations for the present failure to demonstrate differences in pain threshold between those with and without a parental history of hypertension. First, failure to observe group differences may be due to the use of stimuli that was insufficiently painful or distressing to participants. The type of pain stimulus varies among the various studies that have been conducted, and our pain stimulus may not have been sufficiently intense for most participants. For example, 13 out of the 79 participants were not providing pain ratings at the level considered their pain threshold at even the highest stimulation level. This may be due, in part, to the fact that we were unable to give an electrical stimulation greater than $40 \mathrm{~mA}$ for safety and ethical reasons. Individuals were considered to be at their pain threshold when they provided an intensity rating of 50. However, there were individuals who reached the maximum stimulation level of $40 \mathrm{~mA}$ but had not endorsed a pain rating of 50, so we were unable to get an accurate assessment of pain threshold. Second, other types of pain stimuli may produce a more intense reaction, such as nociceptive flexion response threshold task, and therefore may be more likely to elicit group differences in pain threshold. For example, Page and France (1997) examined pain thresholds using nociceptive withdrawal reflex in individuals with and without a parental history of hypertension. The nociceptive withdrawal reflex is a naturally occurring physiological correlate of nociception. Previous 
studies examining hypoalgesia relied on self-report of pain. However, the use of the nociceptive withdrawal reflex provides an objective index of spinal reflex modulation by the brain. There is a close relationship between nociceptive reflex thresholds and subjective pain ratings; hence individuals with decreased sensitivity to pain should demonstrate higher levels of electrical stimulation before showing a reflex. This study found that individuals with a parental history of hypertension had higher nociceptive reflex thresholds than those without a parental history of hypertension. Therefore, the type and intensity of the pain stimulus may be relevant to observing differences among those with and without a parental history of hypertension.

A third explanation as to why our hypotheses were not supported is the strong likelihood of false positives and false negatives in the parental history of hypertension groups. False negatives are individuals who are identified as "negative parental history of hypertension" when, in fact, their parents have hypertension but are unaware of the condition or they do not currently have hypertension, but will go on to develop high blood pressure in the future. The latter situation is not unlikely given the relatively young age of most parents in this sample. Not only were our participants in the $\mathrm{PH}+$ group, on average, older than those in the PH- group, their parents were, on average, 4 years older than parents in the PH- group. This difference in the average age of parents could affect the likelihood of a diagnosis of hypertension. False positives are individuals who are identified as "positive parental history of hypertension" but who do not go on to develop hypertension in the future. This situation is common as a parental history of hypertension is only a moderate predictor of future hypertension, and is associated with an increased 
relative risk of only 1.5 to 2.4 times likelihood of developing hypertension (Wang et al., 2008). Further, this assumes accurate parental reports. Given that we were reliant on selfreport data, parents may also have provided inaccurate information leading to participants being placed in the wrong group.

\section{Limitations and Future Directions}

It is important to note that there are some limitations to our study that need to be considered. We tested a very narrow age range of study participants, so our results may not generalize to other populations. Future studies should conduct median nerve testing on individuals from a more extensive age range to look at differences in median nerve function.

Second, we only tested median nerve function in the dominant arm of participants. Future studies should test median nerve function in both arms, as well as testing other peripheral nerves to fully assess nerve functioning. Also, we only used one type of pain stimulus in our study. Different results may have emerged with another type of pain stimulus (Fillingim \& Maixner, 1996). Future studies may be enhanced through the use of multiple forms of pain stimulation paradigms, such as electrical and thermal stimulation. Thermal stimulation would provide more enduring pain rather than a brief electrical pulse. Though we were unable to confirm a relationship between parental history of hypertension and hypoalgesia possibly due to the low intensity of electrical stimulation, future studies should be conducted to see if other forms of pain stimuli may support that relationship and to help determine the mechanism behind the development of hypertension. 
In summary, results from the present study add to the median nerve research literature because our assessment of median nerve function in normotensive college-aged students implies that impairments in median nerve function may occur as a response to hypertension. These median nerve deficits are not seen in a sample of individuals at risk for hypertension. 


\section{References}

al'Absi, M., Buchanan, T., \& Lovallo, W. R. (1996). Pain perception and cardiovascular responses in men with positive parental history for hypertension. Psychophysiology, 33, 655-661.

al'Absi, M., Buchanan, T.W., Marrero, A., \& Lovallo, W.R. (1999). Sex differences in pain perception and cardiovascular responses in persons with parental history of hypertension. Pain, 83, 331-338.

al'Absi, M., Petersen, K.L., \& Wittmers, L.E. (2000). Blood pressure but not parental history for hypertension predicts pain perception in women, Pain, 88, 61-68.

Bragdon, E.E., Light, K.C., Girdler, S.S., \& Maixner, W. (1997). Blood pressure, gender, and parental hypertension are factors in baseline and poststress pain sensitivity in normotensive adults. International Journal of Behavioral Medicine, 4, 17-38.

Campbell, T.S. \& Ditto, B. (2002). Exaggeration of blood pressure-related hypoalgesia and reduction of blood pressure with low frequency transcutaneous electrical nerve stimulation. Psychophysiology, 39, 473-481.

Campbell, T.S., Ditto, B., Assaad, J., Pihl, R.O., Seguin, J.R., Nagin, D., et al. (2002). A longitudinal study of pain sensitivity and blood pressure in adolescent boys: Results from a 5-year follow-up. Health Psychology, 21, 594-600.

Campbell, T.S., Ditto, B., Seguin, J.R., Sinray, S., \& Tremblay, R.E. (2003). Adolescent pain sensitivity is associated with cardiac autonomic function and blood pressure over 8 years. Hypertension, 41, 1228-1233.

D’Antono, B., Ditto, B., Rios, N., \& Moskowitz, D.S. (1999). Risk for hypertension and 
diminished pain sensitivity in women: autonomic and daily correlates. International Journal of Psychophysiology, 31, 175-187.

Ditto, B., France, J., \& France, C.R. (1997). Risk for hypertension and pain sensitivity in women. International Journal of Behavioral Medicine, 4, 117-130.

Ditto, B., Pihl, R.O., Seguin, J.R., Boulerice, B., \& Tremblay, R.E. (1998). Risk for hypertension and pain sensitivity in adolescent boys. Health Psychology, 17, 249254.

Edwards, L., Ring, C., McIntyre, D., Winer, J.B., \& Martin, U. (2008). Cutaneous sensibility and peripheral nerve function in patients with unmedicated essential hypertension. Psychophysiology, 45, 141-147.

Ferry, S., Silman, A.J., Pritchard, T., Keenan, J. \& Croft, P. (1998). The association between different patterns of hand symptoms and objective evidence of median nerve compression. Arthritis \& Rheumatism, 41, 720-724.

Fillingim, R. \& Maixner, W. (1996). The influence of resting blood pressure and gender on pain responses. Psychosomatic Medicine, 58, 326-332.

France, C. R., Adler, P. S. J., France, J., \& Ditto, B. (1994). Family history of hypertension and pain during blood donation. Psychosomatic Medicine, 56, 5260.

France, C.R., al'Absi, M., Ring, C., France, J.L., Brose, J., Spaeth, D., et al. (2005). Assessment of opiate modulation of pain and nociceptive responding in young adults with a parental history of hypertension. Biological Psychology, 70, 168-174.

France, C. R., Ditto, B., \& Adler, P. (1991). Pain sensitivity in offspring of hypertensives 
at rest and during baroreflex stimulation. Journal of Behavioral Medicine, 14, 513-525.

France, C.R., French, D.J., Page, G.D., Bonk, V.A., Meade, M.A., Stewart, K.M., et al. (1996). Exteroceptive suppression of temporalis and masseter muscle activity is enhanced in offspring of hypertensives. Psychophysiology, 33, 601-604.

France, C.R. \& Stewart, K.M. (1995). Parental history of hypertension and enhanced cardiovascular reactivity are associated with decreased pain ratings. Psychophysiology, 32, 571-578.

Guasti, L., Zanotta, D., Petrozzino, M. R., Grimoldi, P., Diolisi, A., Garganico, D. et al. (1999). Relationship between dental pain perception and 24 hour ambulatory blood pressure: a study on 181 subjects. Journal of Hypertension, 17, 17991804.

Johnson, M.S., Ryals, J.M., Wright, D.E. (2007). Diabetes-induced chemogenic hypoalgesia is paralled by attenuated stimulus-induced fos expression in the spinal cord of diabetic mice. The Journal of Pain, 8, 637-649.

Joint National Committee on Prevention, Detection, Evaluation, and Treatment of High Blood Pressure. (2004). The seventh report of the Joint National Committee of Prevention, Detection, Evaluation, and Treatment of High Blood Pressure (JNC 7). JAMA, 289, 2560-2572.

Melzack, R. (1987). The short form of the McGill Pain Questionnaire. Pain, 30, 191197. 
Myers, C.D., Robinson, M.E., Riley, J.L., \& Sheffield, D. (2001). Sex, gender, and blood pressure: Contributions to experimental pain report. Psychosomatic Medicine, 63, 545-550.

Ong, K.L., Cheung, B.M.Y., Man, Y.B., Lau, C.P., \& Lam, K.S.L. (2007). Prevalence, awareness, treatment, and control of hypertension among United States adults 1999-2004. Hypertension, 49, 69-75.

Page, G.D. \& France, C.R. (1997). Objective evidence of decreased pain perception in normotensives at risk for hypertension. Pain, 73, 173-180.

Radecki, P. (1995). Variability in the median and ulnar nerve latencies: Implications for diagnosing entrapment. Journal of Occupational and Environmental Medicine, 37, 1293-1299.

Sabbatini, M., Bellagamba, G., Vega, J.A., \& Amenta, F. (2001). Effect of antihypertensive treatment on peripheral nerve vasculature in spontaneously hypertensive rats. Clinical and Experimental Hypertension, 23, 157-166.

Sabbatini, M., Vega, J.A., \& Amenta, F. (1996). Peripheral nerve vascular changes in spontaneously hypertensive rats. Neuroscience Letters, 217, 85-88.

Salerno, D.F., Franzblau, A., Werner, R.A., Bromberg, M.B., Armstrong, T.J., \& Albers, J.W. (1998). Median and ulnar nerve conduction studies among workers: Normative values. Muscle \& Nerve, 21, 999-1005.

Shapiro, D., Jamner, L.D., Lane, J.D., Light, K.C., Myrtek, M., Sawada, Y., et al. (1996). Blood pressure publication guidelines. Psychophysiology, 33, 1-12.

Sitsen, J., \& de Jong, W. (1983). Hypoalgesia in genetically hypertensive rats (SHR) is 
absent in rats with experimental hypertension. Hypertension, 5, 185-190.

Stewart, K.M. \& France, C.R. (1996). Resting systolic blood pressure, parental history of hypertension, and sensitivity to noxious stimuli. Pain, 68, 369-374.

Wang, N., Young, J.H., Meoni, L.A., Ford, D.E., Erlinger, T.P., \& Klag, M.J. (2008). Blood pressure change and risk of hypertension associated with parental history. Archives of Internal Medicine, 168, 643-648.

Werner, R.A., Jacobson, J.A., \& Jamadar, D.A. (2004). Influence of body mass index on median nerve function, carpal canal pressure, and cross sectional area of the median nerve. Muscle \& Nerve, 30, 481-485.

World Health Report 2002: Reducing risks, promoting healthy life. Geneva, Switzerland: World Health Organization. http://www.who.int/whr/2002/. 
Appendix A1: Human Participants Informed Consent Form

Title of Research: $\quad$ Nerve Function in Individuals at Differential Risk for Hypertension

Principal Investigator: $\quad$ Diane Turcotte, B.S., Dept. of Psychology, Ohio University

Federal and university regulations require signed consent for participation in research involving human subjects. After reading the statements below, please indicate your consent by signing this form.

\section{Explanation of Study}

Purpose of the research

The purpose of this study is to examine physiological and psychological responses to noxious stimuli (brief electrical shock), and to evaluate individual differences in pain perception and median nerve function. If you agree to be in this study, you will be asked to complete one laboratory session lasting no more than two hours. You will receive two research credits for this session.

Procedures to be followed

In this session you will review the informed consent form and ask any questions which you may have about the study. If you decide to participate, we will ensure that you meet all the study requirements. Major eligibility requirements for participation include (a) 18-30 years of age, (b) good physical health as indicated by the absence of chronic or acute illness, (c) no history of cardiovascular, renal, or pulmonary disease, (d) no history of carpal tunnel syndrome or peripheral neuropathy, (e) no use of prescription pain medication on a daily basis, (f) no use of non-prescription pain medicine 24 hours prior to testing and no consumption of caffeine, alcohol, or nicotine 4 hours before the testing session, (g) no vigorous exercise 4 hours before the session and (h) biological parents available to confirm parental blood pressure history. At this session we will record your biological parents' mailing addresses and phone numbers so that we can mail them a blood pressure questionnaire.

Preparation: Stimulating devices will be attached to your dominant hand and forearm. These devices will be used to deliver brief electrical pulses. Next we will have you sit in a recliner chair and we will attach a blood pressure cuff to your middle nondominant arm to monitor your heart rate and blood pressure.

Determination of Median Nerve Response Threshold: We will determine your median nerve maximum response threshold in the forearm of your dominant arm. We will determine the best location for electrode placement by sending out mild electrical pulses every 4 seconds. Once the site has been located, we will secure the electrode to 
your wrist. The procedure will begin with a mild electrical pulse. After each stimulation you will be asked to rate the stimulation intensity using a scale with anchors of 0 (no sensation), 25 (uncomfortable), 50 (painful), 75 (very painful), and 100 (maximum tolerable). The intensity of electrical stimulation will be increased slowly. At the upper range of stimulation intensities you may experience discomfort or pain from each stimulation. However, the stimulation is extremely brief and leaves no residual discomfort. If you find the stimulation to be too uncomfortable, you can discontinue at any time simply by asking the experimenter to stop.

Determination of Median Nerve Function: After your response threshold is determined, we will determine your median nerve function. 12 electrical pulses will be sent every 7 seconds with the level of electrical intensity that was determined from your response threshold. After each stimulation you will be asked to rate the stimulation intensity using a scale with anchors of 0 (no sensation), 25 (uncomfortable), 50 (painful), 75 (very painful), and 100 (maximum tolerable). The intensity of electrical stimulation will be increased slowly. At the upper range of stimulation intensities you may experience discomfort or pain from each stimulation. More intense levels of stimulation may feel similar to a carpet shock. However, the stimulation is extremely brief and leaves no residual discomfort. This process is repeated three times.

Determination of Pain Threshold: After your median nerve function is determined, we will determine your pain thresholds for electrical stimulation. After each electrical stimulation you will be asked to rate the stimulation intensity using a scale with anchors of 0 (no sensation), 25 (uncomfortable), 50 (painful), 75 (very painful), and 100 (maximum tolerable). When determining your electrical pain threshold, we will ask you to receive a series of stimulations until you give a rating of 50 or greater. This will be repeated three times. The intensity of electrical stimulation will be increased slowly. At the upper range of stimulation intensities you may experience discomfort or pain from each stimulation. More intense levels of stimulation may feel similar to a carpet shock. However, the stimulation is extremely brief and leaves no residual discomfort. If you find the stimulation to be too uncomfortable, you can discontinue at any time simply by asking the experimenter to stop. You will fill out a brief questionnaire following the procedure.

Resting Blood Pressure: After these procedures, we will ask you to sit quietly for fifteen minutes while your blood pressure and heart rate are measured from your nondominant arm at three minute intervals. They will be assessed at $0,3,6,9,12$, and 15 minutes.

Duration of subject's participation

The session will last no more than 2 hours. You may choose to discontinue the study at any time without penalty.

Identification of specific procedures that are experimental 
The procedures in use in this project are well studied and have been used extensively in prior research.

\section{Risks and Discomforts}

The electrical stimulations are likely to elicit temporary increases in heart rate and blood pressure as well as sensations of discomfort or pain. More intense levels of stimulations are similar to a carpet shock. Further, to apply the electrode for electrical stimulation, it is necessary to slightly abrade the skin using a commonly used application gel. Like an exfoliation cream, it takes off the dead skin. In some cases, you might experience redness of the skin in the days following the experiment; however, this redness should go away by itself. If you experience anything more than mild redness or irritation, please contact the experimenter. You may discontinue the procedure at any time for any reason.

Benefits

The main benefit to you is the opportunity to increase your knowledge and understanding of psychological research methods. In addition, you will receive information regarding your heart rate and blood pressure status.

The wider societal benefit is the opportunity to extend previous findings obtained in this laboratory regarding potential differences in pain sensitivity in individuals with and without a genetic risk for hypertension. This information is important in that there may be overlap between the mechanisms responsible for decreased pain sensitivity and risk for blood pressure elevation in at-risk populations. This study will also provide information of the potential role of nerve function in the development of hypertension.

Confidentiality and Records

All information obtained from you will be kept strictly confidential. This information will be identified according to a code number known only to those directly involved with this research project. The key that relates your name to the code number will be destroyed (leaving only code numbers) at the conclusion of the study. Further, any information collected from you will be stored in a locked filing cabinet available only to the research personnel. In the event of publication of the research findings, data from this study will be reported only as an aggregate and therefore no individually identifying information will be published.

\section{Compensation}

You will receive 2 research credits for participation in this session. 
Contact Information

If you have any questions regarding this study, please contact Diane Turcotte, B.S. at (617) 595-6763 or via email at dt361807@ohio.edu. You may also contact the supervisor of the study, Christopher France, Ph.D., at (740) 593-1079 or via email at france@ohio.edu.

If you have any questions regarding your rights as a research participant, please contact Jo Ellen Sherow, Director of Research Compliance, Ohio University, (740) 597-1267.

I certify that I have read and understand this consent form and agree to participate as a subject in the research described. I agree that known risks to me have been explained to my satisfaction and I understand that no compensation is available from Ohio University and its employees for any injury resulting from my participation in this research. I certify that I am 18 years of age or older. My participation in this research is given voluntarily. I understand that I may discontinue participation at any time without penalty or loss of any benefits to which I may otherwise be entitled. I certify that I have been given a copy of this consent form to take with me.

Signature Date

Printed Name

Future Research:

If you are willing to be contacted about participation in future related research projects, please check the box next to ,yes.' Otherwise, please check the box next to ,no.' Your willingness to be contacted about future studies will in no way affect your participation in the current study.
$\square$ yes
no

Signature Date 
Appendix A2: Health History and Parent Contact Form

First Name:

Last Name:

Local Phone Number:

Age:

Sex: Male / Female

Race: American Indian or Alaskan native Asian Native Hawaiian or Other Pacific Islander Black or African American White

Ethnicity: Hispanic or Latino Not Hispanic or Latino

Do you have any significant health problem(s)?

YES

$\mathrm{NO}$

If yes, please describe

Have you ever been diagnosed with low blood pressure or syncope (fainting)? YES

NO

If yes, please describe:

Are you currently taking any prescription or non-prescription medication? $\quad$ YES

$\mathrm{NO}$

If yes, please describe

Have you consumed any caffeine or alcohol today?

NO

YES

If yes, please describe:

Have you had any nicotine (e.g., smoking, chewing tobacco, etc.) today?

YES

NO

If yes, please describe:

Have you engaged in any vigorous exercise today?

$\mathrm{NO}$

YES

If yes, please describe:

\section{PARENTAL HEALTH HISTORY}

1. Was your biological FATHER ever told by his doctor that he:
a) had high blood pressure?
yes
no don't know
b) should take blood pressure medication?
yes no don't know

2. Was your biological MOTHER ever told by her doctor that she:
a) had high blood pressure?
yes
no don't know
b) should take blood pressure medication?
yes
no don't know 
So that we may contact your parents to ask about their blood pressure history, please fill in your parents' address(es) below. We will send them a one page questionnaire that asks about their blood pressure history. We do not reveal any of your personal health information to your parents.

\begin{tabular}{|c|c|}
\hline \multicolumn{2}{|c|}{ Father's Name } \\
\hline Street & Apt. \\
\hline City & State ZIP \\
\hline
\end{tabular}

Father's Phone Number
Mother's Name

\begin{tabular}{lll}
\hline Street & \multicolumn{2}{c}{ Apt. } \\
& & \\
\hline City & State $\quad$ ZIP & \\
& & \\
\hline
\end{tabular}

Mother's Phone Number 
Appendix A3: Ohio Blood Pressure History Survey Forms

\section{FATHER'S FORM}

Because this study is concerned with the effects of a genetic history of hypertension (high blood pressure), this form should be completed by the biological father only.

1. What is your age?

2. How long has it been since you last had your blood pressure checked by your doctor? 0 to 6 months __ 6 to 12 months __ 1 to 5 years __ more than 5 years _ never

3. If you know, what is your typical blood pressure now?

$\overline{\text { systolic }} \overline{\text { diastolic }}$

4. Have you ever been told by a doctor that you had hypertension (high blood pressure)? $\quad$ Yes No Don't Know

If yes, how old were you when you received this diagnosis?

5. Has a doctor ever prescribed medication for you to treat hypertension (high blood pressure)? $\quad$ Yes No Don't Know

If yes, please list the medication(s):

6. Do you suffer from diabetes or kidney disease? $\quad$ Yes No Don't Know If yes, please describe:

7. Do you suffer from any other significant health problems? Yes No Don't Know If yes, please describe:

8. From the list below, please circle any of your biological relatives who were told by a doctor that they had hypertension (high blood pressure) before age 55:

$\begin{array}{llll}\text { Your Mother } & \text { Your Father } \quad \text { Your Sister(s) } & \text { Your Brother(s) }\end{array}$ 


\section{MOTHER'S FORM}

Because this study is concerned with the effects of a genetic history of hypertension (high blood pressure), this form should be completed by the biological mother only.

1. What is your age?

2. How long has it been since you last had your blood pressure checked by your doctor?

_ 0 to 6 months __ 6 to 12 month _ 1 to 5 years __ more than 5 years _ never

3. If you know, what is your typical blood pressure now?

$\overline{\text { systolic }} \overline{\text { diastolic }}$

4. Have you ever been told by a doctor that you had hypertension (high blood pressure)? $\quad$ Yes No Don't Know

If yes, how old were you when you received this diagnosis?

If yes, was your high blood pressure related to pregnancy?

5. Has a doctor ever prescribed medication for you to treat hypertension (high blood pressure)? $\quad$ Yes No Don't Know

If yes, please list the medication(s):

6. Do you suffer from diabetes or kidney disease? Yes No Don't Know If yes, please describe:

7. Do you suffer from any other significant health problems? Yes No Don't Know If yes, please describe:

8. From the list below, please circle any of your biological relatives who were told by a doctor that they had hypertension (high blood pressure) before age 55:

Your Mother $\quad$ Your Father $\quad$ Your Sister(s) $\quad$ Your Brother(s) 
Appendix A4: Numerical Pain Rating Intensity Scale

Intensity Scale

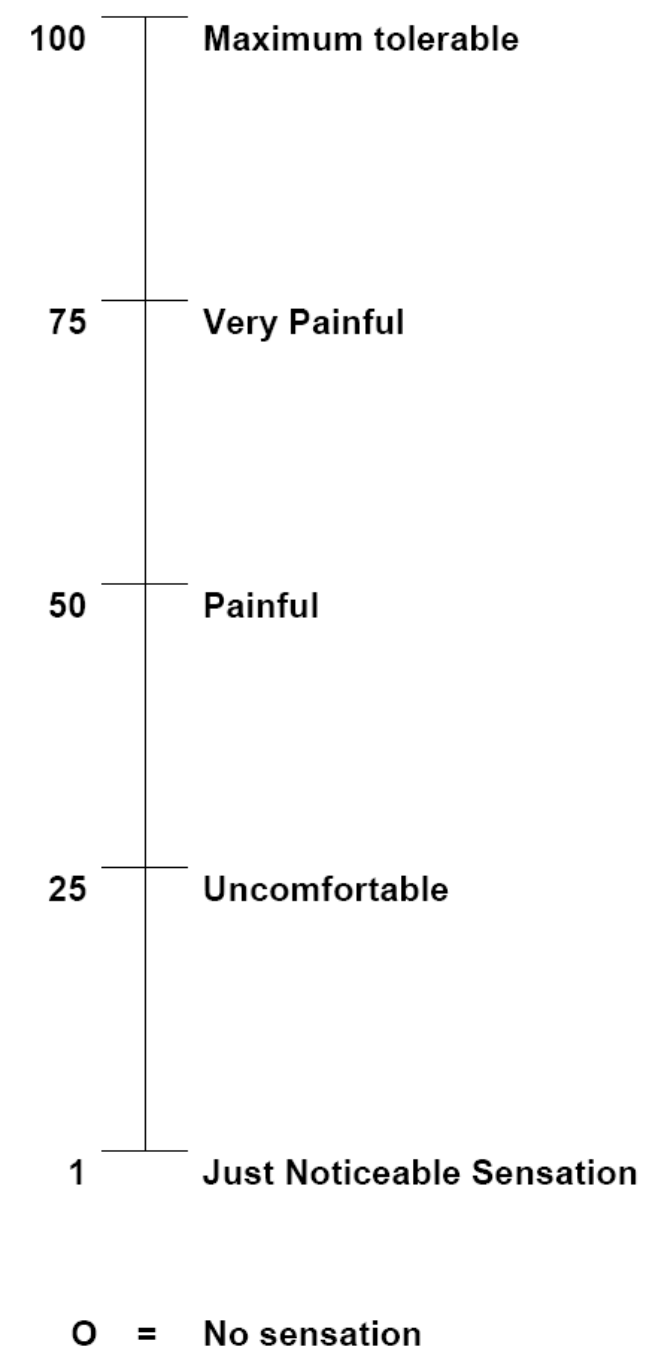


Appendix A5: Parent Letter

Date

XXXXX

XXXXX

XXXXX

\section{Dear XXXXX,}

Your (daughter or son), has participated in our study concerning individual differences in nerve function and stimulation responses in healthy young adults with and without a family history of high blood pressure. This study has been approved by Ohio University's Institutional Review Board. The goal of our research is to learn more about potential mechanisms in the development of hypertension (high blood pressure). Since our main focus is family blood pressure history, we must contact the parents of all participants to request additional information to complete the study.

Your help in completing our investigation would be greatly appreciated. We ask that you take a few minutes to complete the attached questionnaire and return it in the enclosed postagepaid envelope. All responses to the questionnaire remain strictly confidential. To help ensure confidentiality, each questionnaire is identified with a numerical code only. This number is used to combine your responses with the information provided by your child. The key that relates your name to the code number will be destroyed (leaving only code numbers) at the conclusion of the study. Further, any information collected from you will be stored in a locked filing cabinet available only to the research personnel. In the event of publication of the research findings, data from this study will be reported only as an aggregate and therefore no individually identifying information will be published.

By completing the enclosed questionnaire it is understood that you are consenting to the use of this information in our research project. You are, of course, under no obligation to complete this questionnaire. Further, if your child attends Ohio University, his/her grades are in no way related to this decision.

I would like to thank you for your kind attention to this letter. If you require further information, please do not hesitate to email (dt361807@ohio.edu) or telephone (617-595-6763). My supervisor, Chris France, Ph.D., is also available to contact by email (france@ohio.edu) or telephone (740-593-1079).

Sincerely,

Diane Turcotte, B.S.

Graduate Student

Clinical Health Psychology

Enclosure 


\section{Appendix A6: McGill Pain Questionnaire - Short Form}

\section{MPQ-SF}

1) Make a mark along the line that corresponds to the pain intensity that you felt during the previous task?

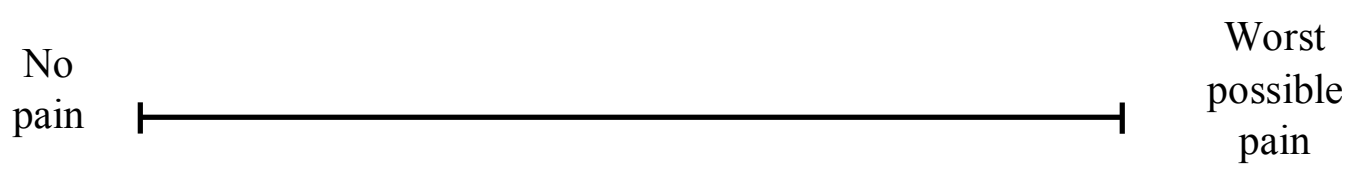

2) Which word best describes your pain during the previous task (choose one)?

\begin{tabular}{ll} 
& No pain \\
& Mild \\
\hline & Discomforting \\
\hline & Distressing \\
\hline & Horrible \\
Excruciating
\end{tabular}

3) Indicate the degree to which each of the following 15 words apply to the pain that you felt during the previous task.

\begin{tabular}{|c|c|c|c|c|c|}
\hline & & $\begin{array}{l}z \\
\text { Z } \\
\frac{0}{0}\end{array}$ & $\frac{3}{\overline{2}}$ & $\begin{array}{l}3 \\
\frac{3}{0} \\
\frac{0}{0} \\
\frac{0}{01}\end{array}$ & $\begin{array}{l}\text { CD } \\
\underset{\mathbb{\Phi}}{\Phi} \\
\frac{\Phi}{\infty}\end{array}$ \\
\hline 1. & THROBBING & (0) & (1) & (2) & (3) \\
\hline 2. & SHOOTING & (0) & (1) & (2) & (3) \\
\hline 3. & STABBING & (0) & (1) & (2) & (3) \\
\hline 4. & SHARP & (0) & (1) & (2) & (3) \\
\hline 5. & CRAMPING & (0) & (1) & (2) & (3) \\
\hline 6. & GNAWING & (0) & (1) & (2) & (3) \\
\hline 7. & HOT-BURNING & (0) & (1) & (2) & (3) \\
\hline 8. & ACHING & (0) & (1) & (2) & (3) \\
\hline 9. & HEAVY & (0) & (1) & (2) & (3) \\
\hline 10. & TENDER & (0) & (1) & (2) & (3) \\
\hline 11. & SPLITTING & (0) & (1) & (2) & (3) \\
\hline 12. & TIRING-EXHAUSTING & (0) & (1) & (2) & (3) \\
\hline
\end{tabular}




\begin{tabular}{|c|c|c|c|c|c|}
\hline 13. & SICKENING & (0) & (1) & (2) & (3) \\
\hline 14. & FEARFUL & (0) & (1) & (2) & (3) \\
\hline 15. & PUNISHING-CRUEL & (0) & (1) & (2) & (3) \\
\hline
\end{tabular}




\section{Appendix B: Supplemental Text}

\section{Methodology for Blood Pressure Measurement}

Shapiro and colleagues (1996) recommend averaging multiple measurements to ensure precision in estimating blood pressure levels. In addition, they encouraged researchers to consider any psychological stressors, such as anticipatory anxiety, that may affect blood pressure levels. Therefore, we concluded the sessions with blood pressure measurements to account for these influential factors.

\section{Body Mass Index as a Covariate}

The covariate was body size as indexed by body mass index $\left(\mathrm{kg} / \mathrm{m}^{2}\right)$ because body size may have an effect on median nerve measurement. Research has shown that obese individuals have slowed conduction in the median nerve; however the mechanism is unclear (Werner, Jacobson, \& Jamadar, 2004).

\section{Sex-related Differences in Pain}

Our results also did not support any sex-related differences in pain threshold. Some previous studies reported higher pain threshold levels in males compared to females (al' Absi, 1999; al' Absi et al., 1996; Myers et al., 2001). We examined if there were any differences in pain threshold by gender regardless of having a parental history of hypertension through analysis of variance. We found no significant differences in pain threshold by gender, $F(1,78)=1.20, p=$ .28 with the average pain threshold for males being 25.7 (10.4) $\mathrm{mA}$ and for females being 23.0 (11.6) mA. We did not observe any differences between two common pain moderators (parental history of hypertension and sex) implying that the issue may lie within the intensity of our pain stimulus. 
Physiological information on how axonal loss may contribute to nociception

Combined with a lack of differences between the two groups in sensory and compound motor median nerve velocities, these findings indicated that hypertension does not affect neuronal myelination but may be associated with axonal loss. In contrast to the central hypoalgesia hypothesis that is often provided in the literature, these findings may provide a simpler explanation for the hypoalgesic responses displayed in individuals with hypertension and possibly in those at risk for hypertension. Specifically, because axonal loss results in deficits in spinal cord activation (Johnson, Ryals, \& Wright, 2007), observed differences in pain perception among individuals with and without hypertension may be due, at least in part, to differences in peripheral processing of pain signals.

\section{Follow-up Analyses}

We examined the relationship between sensory action potential amplitudes and pain threshold through correlational analyses. They were not significantly related, $\mathrm{r}=.065, \mathrm{p}=.60$. We also examined the relationship between systolic blood pressure and sensory action potential amplitudes and the relationship between diastolic blood pressure and sensory action potential amplitudes through correlational analyses. The former analysis was not significantly related, $\mathrm{r}=$ $.107, \mathrm{p}=.35$ and the latter analysis was also not significantly related, $\mathrm{r}=-.040, \mathrm{p}=.73$. 